\title{
COMPARISON BETWEEN POSTOPERATIVE DRAIN OUTPUT AFTER THYROIDECTOMY WITH AND WITHOUT USE OF HARMONIC SCALPEL DEVICE
}

\author{
AMNA JAVED MOEEN, MUHAMMAD SHABBIR AHMAD, NEELAM KHALID, \\ FALAK SHER MAHL, FARMAN ALI \\ Department of General Surgery, Postgraduate Medical Institute/Ameer ud Din Medical College/ \\ Lahore General Hospital, Lahore
}

\begin{abstract}
:
Background: Thyroid gland is among the most important endocrine tissue in human beings, performing multiple functions to maintain homeostasis. Thyroid nodular disease is a frequently encountering problem in surgical OPD that could be malignant or benign. It is more common in females than in males and is expecting that after a decade or so, it will be the $2^{\text {nd }}$ most common malignancy in women. Ultrasound guided fine-needle aspiration (FNA) and core needle biopsy (CNB) are two modalities use to diagnose thyroid swelling preoperatively. Multiple techniques are used to manage thyroid swellings, depending on type and size of thyroid enlargement. Total thyroidectomy, radical and subtotal thyroidectomies are few examples. As thyroid has rich blood supply, ensuring early hemostasis is of vital importance as it directly affects duration of operation as well as visibility of surgical site and intra operative bleeding. Newer techniques include use of harmonic scalpel device that can seal and dissect blood vessels simultaneously by coagulating proteins present in blood vessels, decreasing duration of operation and better hemostasis.

Objective: To evaluate the operative duration, post-operative complications and drain output after thyroidectomy with and without use of harmonic scalpel device.

Methods: Randomized controlled trial was conducted at Surgical Unit 3 of Lahore General Hospital between July 2018 and June 2019. All patients consented before participation in this study. All patients underwent total or near total thyroidectomy and were euthyroid at the time of surgery. All participants were arbitrarily allotted to any of the two study groups using lottery method. All the data was collected using preformed questionnaire and was evaluated through SPSS v 25.

Results: Out of 50 patients 35 partakers were female with mean age group of $47 \pm 4.8$ years. 25 participants were enrolled in group in which Harmonic Scalpel device was used while 25 patients underwent conventional method. Mean duration of thyroidectomy from skin incision to skin closure in group with use of harmonic scalpel was 104.19 \pm 13.67 minutes while in conventional group it was $128.62 \pm 11.76$ minutes. Mean output of fluid/blood in drain post operatively in group treated with harmonic scalpel was $48.82 \pm 16.56$ while in conventional group, postoperative drain output was $89.45 \pm 23.21 \mathrm{ml}$.

Conclusion: Harmonic device is both useful and widely used hemostatic tool in thyroid gland surgery. This device is safe and more compelling than the conventional monopolar diathermy.
\end{abstract}

Keywords: Fine-needle aspiration, Core needle biopsy, Monopolar diathermy

How to cite this article: Moin AJ, Ahmad MS, Khalid N, Mahl FS, Ali F. Comparison between postoperative drain output after thyroidectomy with and without use of harmonic scalpel device. Pak Postgrad Med J 2019;30(3): 91-94

This is an Open Access article distributed under the terms of the Creative Commons Attribution License (http://creativecommons.org/licenses/by/3.0), which permits unrestricted use, distribution, and reproduction in any medium, provided the original work is properly cited.

Correspondence to: Amna Javed Moeen, Department of General Surgery, Postgraduate Medical Institute/Ameer-ud-Din Medical College/ Lahore General Hospital, Lahore

E-mail:dr.amna22@yahoo.com

\section{INTRODUCTION:}

The thyroid gland and hormones produced through it play multifarious parts in tissue development and in the homeostasis of basic physiological processes for example development of body and energy disbursement in vertebrates. It develops from a midline structure in 
the bed of pharynx comprising of foregut endoderm cells which are focused to development of thyroid. These primogenitors of thyroid at that point generates explicitly to follicular cell ancestry which in the end will devise hormone building units - the thyroid cells that blend up into thyroid gland. ${ }^{1}$

Thyroid nodular disease (TND) is frequently encountered medical condition, influencing an enormous number of people, particularly females, subpopulations in districts lacking iodine, old individuals and people having any particular clinical conditions. The predominance of TND is huge, affecting $10-70 \%$ of populace and carcinomas are noted in $3-10 \%$ of patients. ${ }^{2}$

Thyroid nodules are exceptionally prevalent, and thyroid malignant growth is at present the $5^{\text {th }}$ driving carcinoma in females. Continuously 2030, it is evaluated that it will be the second driving malignant growth determination in women and the ninth driving disease conclusion in men. ${ }^{3}$

Two principle procedures in practice to diagnose histopathology of thyroid nodule are ultrasound guided FNA and CNB. Approximately 35\% of FNA samples end up being non-diagnostic or of obscure malignant potential. CNB is the technique which is frequently done after recurrent non-diagnostic FNA or in consolidation with FNA in diagnosing thyroid carcinoma. ${ }^{4}$

Majority of thyroid nodules need excision and various techniques are used to perform that including unilateral or bilateral subtotal thyroidectomy, total thyroidectomy and radical thyroidectomy. ${ }^{5}$ Hyperthyroidism and solitary autonomously functioning thyroid nodule may be managed by lobectomy or nodulectomy. ${ }^{6}$

Secure thyroid surgery demands conscientious hemostasis and optimum management of hemorrhage. Considering the thyroid has enhanced vascularity, early control of bleeding plays a vital role in avoiding intraoperative hemorrhage, gaining ample visibility of the surgical field and to avoid damage to adjacent tissue like parathyroid glands or laryngeal nerves. The primary sources of bleeding are damages thyroid vasculature and thyroid parenchymal bleeding. Hemorrhage (per- or postoperative) may provoke serious complications like seromas and hematomas formation that sometimes subject for possibly fatal asphyxia. Hemostasis is a crucial factor also concluding the recurrence of various different issues, just as enhancing the duration of operation, consequently prolonging the duration of hospital stay and costs. ${ }^{7}$

Various modalities intended to keep abreast surgical hemostasis presently in utilization are: "ligation and suturing (e.g., threads, clips, staplers), coagulation devices (e.g., monopolar and bipolar electrocoagulation), ultrasonic coagulation devices (e.g., Ultracision, Harmonic Scalpel®; Ethicon EndoSurgery, Cincinnati, OH), electroligation sealing (e.g., LigaSure ${ }^{\circledR}$ Vessel Sealing System). Electrosurgical devices use thermal energy to denature proteins and the warming of the surgical field because of lateral dispersion may damage nearby imperative structures". In past few years, studies have been trying to find out new devices with less spread of heat, in striving to diminish intraoperative complications and reduce duration of operation. Among these devices main focus is on the Harmonic Scalpel (HS) as it is most established and concentrated hemostatic device. "Among the Ultracision system devices, the CS14C is the most frequently utilized instrument". 8

Harmonic scalpel ("focus" and reformed variety "focus+") is one of the fundamental instruments for surgical concurrent dissection and tissue coagulation which grant dissection and hemostasis by focused use of ultrasonic waves and permits minimally invasive surgical techniques with insignificant horizontal thermal distribution and, consequently, nominal surrounding tissue destruction. ${ }^{9}$ The harmonic scalpel utilizes mechanical ultrasonic energy to concurrently dissect and provide hemostasis to blood vessels by denaturing and coagulating collagen fibers. ${ }^{10}$

Restricted amount of researches have assessed in one analysis, the efficiency of the harmonic scalpel, and conventional technique. This study utilizes both techniques and updates the relative efficacy of these modalities.

\section{METHODS}

Single-center, prospective, randomized control trial was conducted Surgical Unit 3 of Lahore General Hospital. Written informed consent was acquired from every one of the participants. All participants were undergone from near total or total thyroidectomy and were euthyroid at the time of surgery. Participants organized for elective thyroidectomy under general anesthesia and were assessed from July 2018 to June 2019. Age group of 20-69 years and ASA physical status I-II. Morbidities (e.g., coagulopathy, diabetes, hypertension, ischemic heart disease).

After enrollment, all participants were randomly assigned to one of the two study groups using lottery method. 25 participants were enrolled in group in which Harmonic Scalpel device was used while 25 underwent conventional method. All the data was collected using preformed questionnaire and was evaluated through SPSS v 25. 


\section{RESULTS:}

In this study out of 50 patients, $15(30 \%)$ were male and $35(70 \%)$ were female with mean age group of $47 \pm 4.8$ years. Majority of patients $42(84 \%)$ were from Lahore while $8(16 \%)$ were from other cities of Punjab.

Among 50 patients, $38(76 \%)$ patients were diagnosed as simple benign multinodular goiter, 10 (20\%) patients were turned out to be having papillary carcinoma of thyroid while $2(4 \%)$ patient was diagnosed as follicular carcinoma of thyroid.

Harmonic scalpel device was used in $25(50 \%)$ patients while conventional method was used in 25 (50\%) patients. Mean duration of thyroidectomy from skin incision to skin closure was $104.19 \pm 13.67$ minutes while through conventional method; time consumed was $128.62 \pm 11.76$ minutes.

Mean drain output of patients with use of harmonic scalpel device was $48.82 \pm 16.56 \mathrm{ml}$ while with conventional technique; drain output was $89.45 \pm$ $23.21 \mathrm{ml}$. (Figure 1 showing drain output)

Figure 1: Drain Output

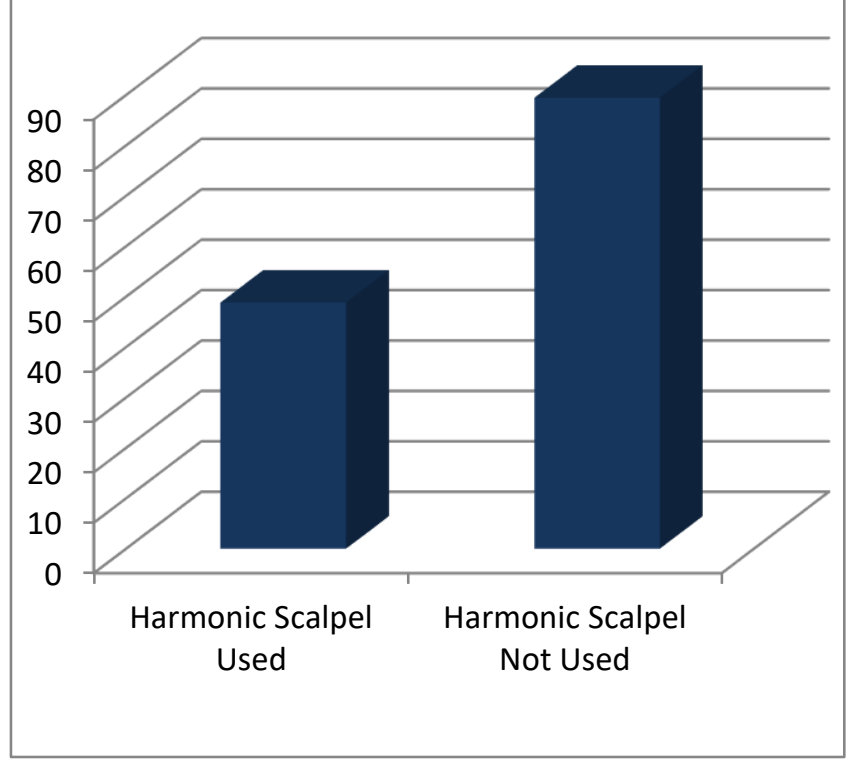

Hematoma was formed in only $1(2.1 \%)$ patient who underwent thyroidectomy without use of Harmonic scalpel device. It was identified before patient developed airway obstruction and was evacuated and hemostasis was secured. Seroma was formed in 2 $(4.25 \%)$ patients, 1 from each group, showing no association with or without use of harmonic scalpel device. Recurrent laryngeal nerve injury was seen in 1 (2.1\%) patient who underwent conventional operative technique. Hyperparathyroidism leading to hypocalcemia was seen in total $3(6.38 \%)$ patients, 1 patient in which harmonic was used while in 2 patients who underwent conventional technique. (Table 1)

Table 1 : Comparison of Complications

\begin{tabular}{lll}
\hline Complications & $\begin{array}{l}\text { Harmonic } \\
\text { Used }\end{array}$ & $\begin{array}{l}\text { Harmonic } \\
\text { Not Used }\end{array}$ \\
\hline Hematoma Formation & 0 & 1 \\
Seroma Formation & 1 & 1 \\
Recurrent Laryngeal Nerve & 0 & 1 \\
Injury & & \\
Hypoparathyroidism & 1 & 2 \\
\hline
\end{tabular}

\section{DISCUSSION}

Thyroid enlargement is a frequently encountering problem all over the world. Male to female ratio in our study was approximately 2.3:1 while in a study done in Greece also shows close ratio between male and female i.e. 3:1. This finding suggests thyroid diseases are more prevalent in females than in male patients. ${ }^{11}$

Ratio of papillary thyroid cancer to follicular thyroid carcinoma in our study was 9:1 while in a study done at Mansoura University, Egypt was 5.8:1.

Due to limitation of small sample size, significance of this finding in our study is questionable but suggests papillary carcinoma of thyroid is commoner than follicular type of thyroid malignancy. ${ }^{12}$ Meta-analysis done at China Medical University revealed that use of harmonic device significantly reduces duration of surgery, while in our study this is also evident that use of energy device reasonably decreases duration of operation. ${ }^{13}$ Decrease in drain output seen with use of harmonic scalpel device as compared to conventional method, in our study. Similar results were seen in a study done in Turkey, enforcing that use of harmonic scalpel seal blood vessels enough that chance of postoperative collection is minimal. ${ }^{14}$

Fewer complications are noted with use of harmonic scalpel in our study. Identical results were discussed in a meta-analysis done at China Medical University. ${ }^{15}$ As well as study done at Göztepe Training and Research Hospital Turkey. This represents harmonic scalpel is a dependable and secure device and its use is more effectual as compared to conventional method. ${ }^{16}$

\section{CONCLUSION}

Our results suggest that the Harmonic scalpel device is both effective and widely used hemostatic and dissecting tool in surgeries of thyroid gland. This device is a lot secure and more compelling than the more conventional monopolar diathermy. However the 
clinical value of Harmonic Scalpel Device in thyroid surgery needs to be further investigated.

\section{ETHICAL APPROVAL}

The study was approved from Ethical Review Committee of Postgraduate Medical Institute, Lahore, Pakistan.

\section{REFERENCES}

1. Mikael N, Henrik F. Development of the thyroid gland, The Company of Biologists Ltd | Development (2017) 144, 2123-2140 doi:10.1242/ dev.145615

2. Kosma W, Adam S, Marek R. Comparison of diagnostic yield of core-needle and fine-needle aspiration biopsies of thyroid lesions: Systematic review and meta-analysis, Eur Radiol. 2017 Jan;27(1):431-436. Epub 2016 Apr 18.

3. Bryan R, Haugen, MD. 2015 American Thyroid Association Management Guidelines for Adult Patients With Thyroid Nodules and Differentiated Thyroid Cancer: What Is New and What Has Changed? Cancer. 2017 Feb 1;123(3):372-381. doi: 10.1002/cncr.30360. Epub 2016 Oct 14

4. Christoph F, Thomas M, Jörg B, Yi D, Giovanni M, Maija R, et al. Statement and recommendations on interventional ultrasound as athyroid diagnostic and treatment procedure, Ultrasound Med Biol. 2018 Jan;44(1):14-36.doi:10.1016/j.ultrasmedbio.2017.08. 1889. Epub 2017 Nov 7.

5. Kuan-Chen C, Usman I, Phung-Anh N. The impact of different surgical procedures on hypoparathyroidism after thyroidectomy A population-based study, Medicine (Baltimore). 2017 Oct;96(43):e8245. doi: 10.1097/MD. 0000000000008245.

6. René GH. Benign nodular thyroid disease Surgical Treatment: Evidence-Based and Problem-Oriented.

7. Luca R, Gianfranco D ,Caterina B, Neve Aurora B, Serafino V, Walter R, et al. Complications in thyroid surgery. Harmonic Scalpel, Harmonic Focus versus Conventional Hemostasis: A meta-analysis, Int J Surg. 2016 Apr;28 Suppl 1:S22-32. doi: 10.1016/ j.ijsu.2015.12.050. Epub 2016 Jan 6.

8. Luca R, Gianfranco D , Caterina BNAB, Serafino V, Walter R. Complications in thyroid surgery. Harmonic Scalpel, Harmonic Focus versus Conventional Hemostasis: A meta-analysis, Int J Surg. 2016 Apr;28 Suppl 1:S22-32. doi: 10.1016/ j.ijsu.2015.12.050. Epub 2016 Jan 6.
9. Ruggiero R, Docimo G, Bosco A, Lanza Volpe M, Terracciano G, Gubitosi A. et al. Update on sutureless thyroidectomy, G Chir Vol. 39 - n. 1 - pp. 45-50 January-February 2018

10. Yingwei L, Xi i, Jianwei D, Weifeng S, A comparison of surgical outcomes and complications between hemostatic devices for thyroid surgery: a network meta-analysis, Eur Arch Otorhinolaryngol DOI 10.1007/s00405-016-4190-4193

11. Vasileiadis I, Boutzios G, Karalaki M, Misiakos E, Karatzas T, Papillary thyroid carcinoma of the isthmus: Total thyroidectomy or isthmusectomy?, The American Journal of Surgery (2017), doi: 10.1016/j.amjsurg.2017.09.008

12. Engy M. Aboelnaga, Ahmed RA. Difference between papillary and follicular thyroid carcinoma outcomes: an experience from Egyptian institution, Cancer Biol Med 2015;12:53-59. doi: 10.7497/j.issn.20953941.2015.0005

13. Yingwei L, Xi L, Jianwei D, Weifeng S, A comparison of surgical outcomes and complications between hemostatic devices for thyroid surgery: a network meta-analysis, Eur Arch Otorhinolaryngol DOI 10.1007/s00405-016-4190-4193

14. Oktay Y, Mustafa D, Ahmet Y, Rafet Y, Tuba Atak, Harmonic Scalpel Compared to Conventional Hemostasis in Thyroid Surgery, Indian $\mathbf{J}$ Surg (January-February 2014) 76(1):66-69 DOI 10.1007/s12262-012-627-630

15. Yingwei L, Xi L, Jianwei D, Weifeng S, A comparison of surgical outcomes and complications between hemostatic devices for thyroid surgery: a network meta-analysis, Eur Arch Otorhinolaryngol DOI 10.1007/s00405-016-4190-4193

16. Oktay Y, Mustafa D, Ahmet Y, Rafet Y, Tuba Atak, Harmonic Scalpel Compared to Conventional Hemostasis in Thyroid Surgery, Indian J Surg (January-February 2014) 76(1):66-69 DOI 10.1007/ s12262-012-627-630

\section{AUTHORS' CONTRIBUTION:}

AJM: Manuscript writing

MSA: Interpretation of data

NW: Study Design

FSM: Introduction

FA: Result Interpretation 